\title{
Application of Cognitive and Socio-Cultural Theories in CALL
}

\author{
doi:10.3991/ijet.v6i2.1564 \\ Mustafa Akın Güngör, Müzeyyen Nazlı Demirbaş \\ Gazi University, Ankara, Turkey
}

\begin{abstract}
Since it is quite difficult in traditional learning atmospheres for the learners to be exposed to the target language adequately in foreign language acquisition, CALL in which virtual environment is designed in more appropriate way has given rise. Two main paradigms, cognitive model and socio-cultural theory, have also been adopted in CALL. Moreover, rather than applying one theory, combination of these paradigms is unavoidable. However, application of this combination is challenging in practice, as these two theories have different principles. Furthermore, when it comes to online education, it turns into more challenging process. In this poster this combination is presented with the help of sample applications from Gazi University.
\end{abstract}

Index terms-cognitive FLA, socio-cultural theory, the effectiveness of CALL tasks

\section{INTRODUCTION}

People need to learn English as a lingua franca to keep up with the cultural, social and technological changes and developments in various areas in our global world. The ability to speak in English is the very heart of what it means to be able to use that language. Our ideas, personality and knowledge of the world are transmitted through our spoken performance of that target language. Likewise, English as an international language has been taught for ages to set up international relationships in politics, economics, education, science, tourism, art, communication, etc. in Turkey. Due to the birth of this necessity, teaching English as a foreign language communicatively has gained significance in our country as well as in the world. According to Chapelle (2001), technology has the responsibility to affect language education in terms of developing communicative competence in second language learning. In addition, Pallof and Pratt (2007) state that the present educational models, approaches and opportunities are not adequate for learners' needs as the technology advances. Moreover, advanced technology enables new trends and concepts in foreign language teaching. Hampel and Lamy (2007) claim that thanks to this technology, too main paradigms have developed in foreign language teaching within computer assisted language learning (CALL), one of which is cognitive theories, the second one is derived from socio-cultural theories. Cognitive theories represent intrapersonal process of language acquisition; in contrast, socio-cultural theories focus on interpersonal process of second language acquisition. They claim that learners are in need of new and different roles, relationships, skills and resources so it is required to make use of the advantages and facilities of technology to be developed cognitively and communicatively in English.

\section{Computer Assisted Language LeArning (CALL)}

Chapelle (2001) thinks that interactive CALL, which provides language learners from different parts of the yeld topractice the target langyage and to communicate in a neutral atmosphere, provides various texts to skim or scan, videos to watch and listen to or comment on, namely, linguistic input and communicative competence. Learners have the opportunity to interact with their peers from different parts of the world and to be exposed to authentic materials such as original visuals, written materials and multimedia depending on their levels. What's more, they have the chance to meet various cultures across the boarders and to be more open-minded and accustomed to innovations in virtual environment. By this way, interaction can also be developed among the learners through the use of the technology. Learners are supposed to construct the course depending on the feature of the virtual or online environment not attend the courses regularly as it happens in face to face or traditional classes; therefore, learner autonomy is on the edge of developing better and better.

\section{A. Virtual Environment}

According to Lamy and Hampel (2007), knowledge is composed of related activities and participation in cultural and social practices is indispensable so in fact learning a foreign language is to deal with target language environment which is designed with cultural, societal and institutional practices. Therefore, this indispensable part should also be taken into consideration in virtual environment design. Bach, Haynes and Smith (2007) imply some principles which are appropriate for virtual environment in online education (Bach, Haynes \& Smith, 2007; 94):

- Gain attention

- Inform of learning objective

- Stimulate recall of prior learning

- Present stimulus material

- Provide learner guidance

- Elicit performance / provide feedback

- Asses performance

- Enhance knowledge retention and transfer

- Appeal to learners interest

In order to gain learners' attention in online education, there should be attractive tools, materials and special design software such as videos, PowerPoint presentations and interactive visuals. Also those materials are to stimulate learners' mind and raise their curiosity and interest. In virtual environment, learners had better be aware of objectives of class and activities clearly. Therefore, if it is needed, tutors make objectives clear to the learners. As Piaget (1972) suggests, individual's mind combines new knowledge with the prior one, namely, they adapt to the world through accommodation and assimilation. Considering this fact, virtual lessons should provide the learners with the opportunity of sharing their prior knowledge in their learning process. The whole system in virtual environment should respond to learners' needs, to illustrate, giving them clear instructions for various activities, lead- 
ing them to collaboration and co-operative study and reminding them where their level or learning should be at the end of each course. What's more, virtual environment should be designed to assess learners' motivation, interaction within the system and reaction to the tasks, and the result of these assessments should be taken into consideration to appeal learners' interests and to determine the subjects and tasks accordingly. In addition, the learners should be given as many opportunities as to assess both themselves and their partners especially in collaborative works. For instance, tests, tasks and etc. learners should be provided with various writing assessments, tutoring and different collaborative and cognitive projects. Virtual environment should also evaluate how knowledge is used by learners in practice and supply different situations to use knowledge in.

\section{B. Interaction in CALL}

Pallof and Pratt (2007) think that even though virtual environment offers many advantages to learners who are shy or reluctant to contact with other learners, when this desire turns into virtual isolation, this becomes a great obstacle for learning process. In contrast to classrooms, it's much easier to lose learners and understand their absence in virtual environment. Interaction level contributes to participation of learners and productivity of learning process. Lamy and Hampel (2007) state that cognitive theories which are based on input and output cycle emphasize the importance of interaction in exchanging knowledge between peers and between learners and teachers. The case is the same for socio-cultural theories, too. Vygotsky (1978) states that;

Interaction with others, especially with peers and teachers, is necessary for children's learning; under adult guidance or in collaboration with more capable peers they learn to solve problems independently. (1978; 86)

\section{Cognitive TheORY}

In cognitive theories for foreign language acquisition, there are three components of learning process; input, output and interaction. According to Ellis (2000), acquisition is a product of processing input and output. In her point of view, input is the language that the learner is exposed to and the output is the language the learner produces. Schmidt (1990) states that comprehensible input is defined by Krashen as a form of input which is just a little beyond the learners' competence but easy enough to be understood. About the form of input, there are two different views. Krashen (1985) considers meaningful activities as a base of function in foreign language acquisition. However, interaction hypothesis emphasizes the interaction to convey and to negotiate the meaning. Gass, Mackey and Pica (1998) claim that input affects learners mostly if it becomes the part of the interaction with others rather than with a text. Comprehensible input is indispensable part of foreign language acquisition. Lamy and Hampel (2007) consider the last component of learning process in cognitive theory (output) as the production of language by learners. With the help of interaction, learners internalize the knowledge given via input and they come up with their own sentences in target language. The virtual environment should check this output and if it is required, the cognitive learning process is recycled. If the output or learners' production is appropriate then this output turns into a new input for new cognitive learning cycle.

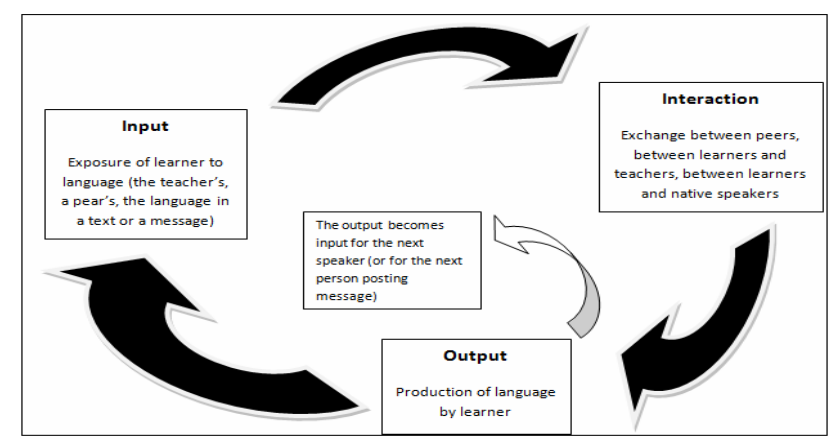

Figure 1. (taken from Lamy and Hampel,2007)

However, in this process especially for output, learners' interests and differences should be taken into consideration because as it is known, each learner is unique and that their output will be new input for new cognitive learning cycle unavoidably affects the learning process. Thus, learners' autonomy should be emphasized in this point.

\section{A. Learner Autonomy}

According to Pallof and Pratt (2007), online learning offers learners chance to practice and acquire the skills needed for communicative competence as well as to get to know their own learning styles, their strong and weak parts in the target language and to study in collaboration with their partners who are geographically distant to them. During this process, they become more competent in their language skills and social interaction, and feel selfconfident. Chapelle (2001) believes that materials and educational methods should be designed considering the needs and interests of the learners to make them more autonomous learners. Hereby, autonomous learners are meant to be the individuals who:

- have the sufficient understanding of language learning to understand the purpose of the pedagogical choices,

- are able to formulate their own learning objectives,

- are able to make use of appropriate learning strategies,

- are able to monitor their use of strategies,

- are able to monitor their own learning.

(Dickinson, 1993;41)

These conditions can be supplied through the precise use of CALL.

\section{SOcio-Cultural THEORY}

Goodyear et al.(2004) state that participation in community or learning through cooperation and collaboration are indispensable part of networked learning. In this approach, interaction is a part of social terms; however, in cognitive theories interaction is a means of relationship between internalized input and output. Lamy and Hampel (2007) emphasize the fact that socio cultural theory associates psychological process with individuals' social being. Thus interaction is the base of learning process in socio cultural theory as Vygotsky (1978) states, interaction with others is indispensable for learning with the help of guidance or capable peers to solve problems related to learning process. Virtual environment provides many opportunities for learners to interact, to study in collaboration and to understand the cultural perspectives of the 
target language with the help of technological devices and special designed tools such as virtual meeting programs, notice boards and even messengers. Especially meeting programs is quite beneficial to motivate learners and to raise their curiosity towards the system because thanks to these programs learners engage with their peers and teachers beyond the computer screen. Lamy and Hampel (2007) emphasize the importance of computer conferencing which allows to connect learners and teachers by offering them new possibilities to practice language and to share other cultures and backgrounds.

\section{CONCLUSION}

Even if these two learning theories differ in some aspects, interaction is their common point. In cognitive theory, interaction means psychological process and internalization of knowledge through input provided in target language. In this point, in virtual environment, learners' interest and their ways of getting knowledge should be taken into consideration. Therefore, in tasks and activities they should have enough opportunities to behave autonomously. This helps them feel self relevant, successful and self motivated in learning. Online education which is also derived from mainly constructive approach should provide learners to take their own learning responsibilities; however, learning environment should be designed to provide any guidance when they need. Thus target language which is an input should be given in a way of activating learners' interests and eliciting information from them in context. From the perspective of socio cultural theory, cultural elements of the target language had better be adapted in the context which is also input for learners. By this way, interaction will be facilitated among the peers. Comprehensible checking questions should be used especially in virtual classes in order to identify whether input is assimilated and accommodated successfully or not through interaction. If it is necessary, the teacher should encourage learners more and more to study in collaboration and cooperation. As the language that learners produce will be a new input for them, the teacher should take the way in which learners internalize the knowledge into consideration. Thus in virtual environment, learners should be encouraged to share their opinions and culture. To achieve this, special designed tools like opinion poll, forum sites, chat boards should be used. Also in order to check whether learners' internalization of knowledge is sufficient or not, learners should get into contact with teachers immediately whenever they need. Due to this reason, email or other tools could be preferred to raise the level of interaction between teacher and learners. In this way, one of the problematic issues in online education which is low motivation in long term process could be overcome. In order to motivate learners in long term process, some virtual meetings or classes in which the priority is to provide opportunity for learners to contact with teacher and peers immediately and affectively could also be used. In these classes, the aim is to motivate learners and to make learners active within the system rather than any linguistic aim. To illustrate, observations in Gazi University Distance Education Language School proves that learners perform the tasks more successfully and participate in classes more willingly and actively on the days which they have virtual classes as it is shown in Figure 2. below;

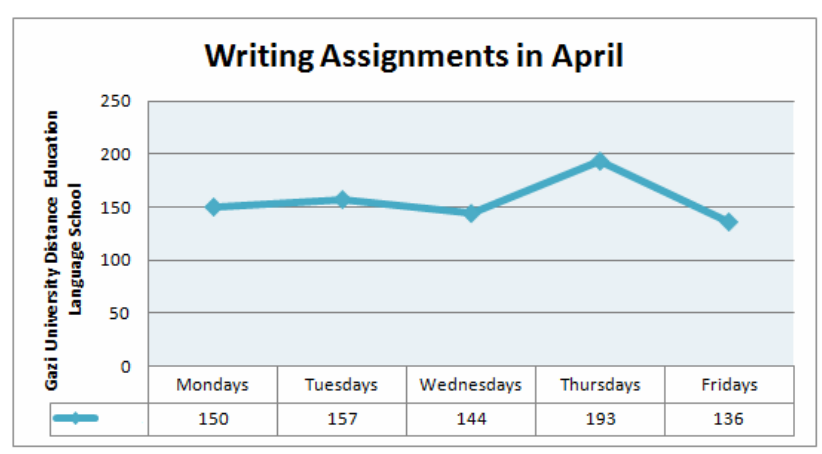

Figure 2. writing assessment in April

In Gazi University Distance Education Language School which is based on constructive approach and in which learners are expected to study and to do their assignments according to their study plans that are unique for each learner, it is observed that thanks to interaction in virtual classes they study more and use the virtual system more on those days. On the days which are Tuesday and Thursday, our learners in Gazi University Language School have grammar support classes in which participation rate is the highest whereas on the other days; Monday, Wednesday and Friday, they have different speaking classes in which participation rate is low. To sum up, even if two theories have different principles and philosophy, interaction is at the heart of both of them. Interaction is also a bit problematic issue in online education as far as it has been observed. In order to handle this issue, different activities, web tools should be preferred and during virtual environment design, it is vital to give opportunity to learners to behave autonomously.

\section{REFERENCES}

[1] Bach, S., Haynes, P.,Smith, J.(2007) Online Learning and Teaching in Higher Education, Open University Press, McGrawHill Companies.

[2] Chapelle, C. A. (2001) Computer Applications in Second Language Acquisition; Foundations for Teaching, Testing and Research, Cambridge: Cambridge University Press.

[3] Dickinson, L. (1993) Talking Shop: Aspects of autonomous learning. ELT Journal, 47 (4)

[4] Ellise, R (2000) Task Based Research and Language Pedagogy, Language Teaching Research 4(3)

[5] Goodyear, P., S. Banks, V. Hodgson and D. McConnell (2004) Research on Networked Learning, Advances in Research on Networked Learning

[6] Grass, S. M., A. Mackey and T. Pica (1998) The Role of Input and Interaction in Second Language Acquisition, Modern Language Journal 82:299-307

[7] Krashen, S. (1985) The Input Hypothesis: Issues and Implications, Harlow: Longman.

[8] Lamy, M.N., Hampel, R. (2007) Online Communication in Language Learning and Teaching, Palgrave Macmillan. doi:10.1057/9780230592681

[9] Pallof, R,M., Pratt, K. (2007) Building Online Learning Communities, Effective Strategies for the Virtual Classroom $2^{\text {nd }}$ ed. Jossey-Bass, USA.

[10] Piaget, J. (1972) The Psychology of the Child, New York: Basic Books.

[11] Van Lier, L. ( 2002) An ecological- semiotic Perspective on Language and Linguistics in C.Kramsch, Language Acquisition and Language Socialization

[12] Vygotsky, L. S. (1978) Mind in Society: The Development of Higher Psychological Process, Cambridge, MA: Harvard University Press. 


\section{SHORT PAPER}

\section{APPLICATION OF COGNITIVE AND SOCIO-CULTURAL THEORIES IN CALL}

\section{AUTHORS}

M. A. Güngör (mustafaakingungor@hotmail.com), Instructor is with Gazi University School of Foreign Languages, Gazi University Gölbaşı Campus, Gölbaşı/Ankara 06830 TURKEY,

M. N. Demirbaş (mnazlidemirbas@gmail.com), Research Assistant, Gazi University ELT Department, Gazi
University Beşevler, Teknikokullar/Ankara 06500 TURKEY.

This paper is an extended version from a contribution at the International Conference ICL2011, held from 15 - 17 September 2010 at University of Hasselt, in Hasselt, Belgium.

Received $7^{\text {th }}$ February 2011 . Published as resubmitted by the authors May $16^{\text {th }}, 2011$ 